\title{
Spectral albedo of snow-covered first-year and multi-year sea ice during spring melt
}

\author{
Roger A. De Abreu, \\ Department of Geography, Earth Observations Laboratory, University of Waterloo, Waterloo, Ontario N2L 3G1, Canada \\ DAVID G. BARBER, \\ Department of Geography, Centre for Earth Observation Science, University of Manitoba, Winnipeg, Manitoba R3T 2.V2, Canada \\ Kevin Misurak and E. F. LeDrew \\ Department of Geography, Earth Observations Laboratory, University of Waterloo, Waterloo, Ontario N2L. 3G1, Canada
}

\begin{abstract}
Surface spectral-albedo data collected over snow-covered first-year and multi-year sea ice under diffuse sky conditions during the springtime transition are examined. Of specific interest is the relationship between changes in the visible and near-infrared albedo of sea ice and concurrent changes in the geophysical characteristics of the ice volume. With the onset of melt conditions, visible and near-infrared sea-ice albedo decreased due to physical changes within the snow and ice volumes. Visible albedo was found to be sensitive to changes occurring throughout the sea-ice volume, while the near-infrared albedo appeared most influenced by nearsurface conditions.
\end{abstract}

\section{INTRODUGTION}

The fraction of incident solar radiation reflected from a snow-covered sea-ice surface is intimately linked to the geophysical characteristics of the snow/ice volume. This fraction, or albedo, exhibits certain spectral characteristics in the visible $(0.39-0.77 \mu \mathrm{m})$ and infrared regions $(0.77-4.0 \mu \mathrm{m})$ of the solar spectrum that evolve through the annual cycle of sea-ice growth and decay Grenfell and Perovich, 1984; Allison and others, 1993). The desire for both improved parameterizations of sea-ice albedo in environmental-change models and the development of remote-sensing methodologies to map surface albedo at both solar and microwave frequencies has heightened the importance of understanding the relationship between spectral albedo and the geophysical characteristics of the sea-ice volume. The purpose of this investigation is to examine the temporal change in spectral albedo over snow-covered sea-ice surfaces during the Arctic springtime transition and relate this transformation to observable changes in the geophysical properties occurring in the volume throughout this period.

\section{METHODS}

Field observations were made over first-year and multiyear sea-ice surfaces during the spring segment (April June) of the SIMMS 1993 experiment $\left(74.59^{\circ} \mathrm{N}\right.$, $94.71^{\circ} \mathrm{W}$ ) in the fast-ice regime of the Lancaster Sound/ Barrow Strait region in the Arctic Archipelago. For a detailed description of the SIMMS project see LeDrew and Barber (1994). Two major sampling sites were located over smooth first-year ice (FYI) and on a conglomerate multi-year-ice (MYI) floe. A portable field spectrometer (Analytical Spectral Devices, Inc.) was used to collect surface spectral-albedo and irradiance measurements in the spectral range $0.34-1.06 \mu \mathrm{m} \quad(512$ channels). A cosine receptor was used to provide the instrument with a $180^{\circ}$ field of view. Measurements were taken under clear and diffuse irradiance conditions to maximize the likelihood of a stable irradiance field. However, spectral albedos collected under clear skies over snow surfaces appeared to be overestimated due to a yet undetermined wavelength-dependence of the cosine response of the cosine receptor. Since this dependence is presently unknown, only data from overcast days with no visible solar disk are presented here (with exceptions noted below).

After cach albedo measurement a detailed examination of the snow/ice volume was made via snow-pit measurements. Snow and ice physical-property measurements were made in dedicated sampling areas called "crystal pits") every 3 days at approximately solar noon. Crystal pits consisted of a small rectangular excavation of approximately $0.5 \mathrm{~m}^{2}$. Sampling was done at vertical intervals of $2 \mathrm{~cm}$ at the FYI site and $3 \mathrm{~cm}$ at the MYI site. Snow wetness was measured using a capacitance plate (dielectric method). Density was measured using a gravimetric approach. In situ macrophotography was used to obtain snow-grain photographs at each sampling level. Snow grain-size was determined automatically from 
the photographs after digitization. In this study, we consider the smallest discernible particle in the snow cover to be a snow grain. Snow-grain radii in the crystal photographs were determined by assuming that the grains were area-equivalent spheres. Crystal photography was stopped on day 158 because of difficulty in keeping the samples from melting. Crude measurements of grain shape and diameter were continued by visual analysis of grain-size and shape through the use of a magnifying glass and gridded paper. Sampling events are referred to here by their Julian day. Solar zenith angles during the sampling period ranged from $56^{\circ}$ (day 134) to $51^{\circ}$ (day 173). During SIMMS'93, daily average air temperatures ranged from $-19^{\circ}$ to $2^{\circ} \mathrm{C}$ (Fig. 1).

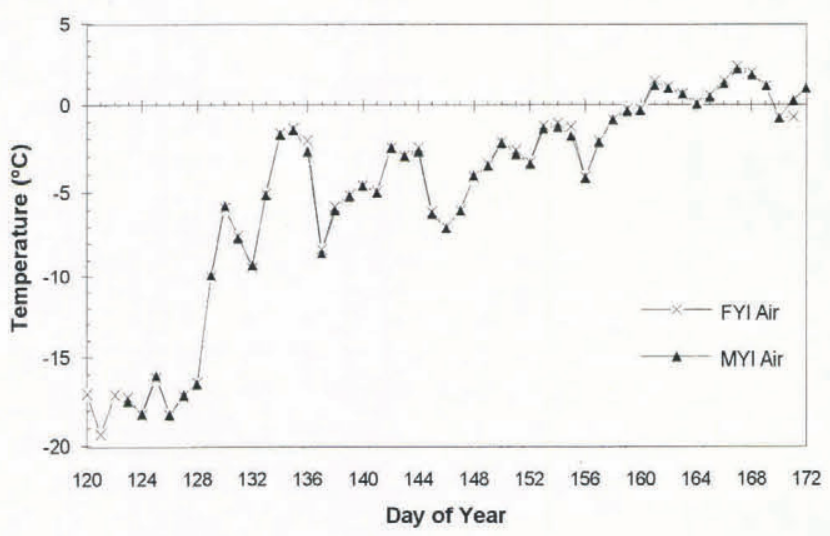

Fig. 1. Daily average air temperature during SIMMS'93.

\section{RESULTS AND DISCUSSION}

Observations reveal that FYI and MYI surfaces change dramatically with the onset of melt conditions. We examine the seasonal change in surface albedo within the context of three stages: early, transitional and late.
Figure 2a and b show the spectral-albedo data collected over FYI and MYI sites respectively. The data have been truncated to $0.4-1.0 \mu \mathrm{m}$ to eliminate noise at the limits of the detector. Table 1 provides albedos averaged over the visible $\left(\alpha_{\text {vis }}\right)(0.40-0.77 \mu \mathrm{m})$ and the near-infrared $\left(\alpha_{\text {nir }}\right)$ $(0.77-1.0 \mu \mathrm{m})$ regions of the instrument's spectral range. Table 1 also includes the geophysical measurements collected after each albedo measurement.

\subsection{Early stage}

With the onset of melt conditions, Arctic sea ice is typically covered by an old snow cover deposited the previous autumn. Spatially, the depth of the volume can vary over metres depending on the surface topography and aeolian processes. In the early stage, snow covers have low liquid-water contents as air temperatures are well below $0^{\circ} \mathrm{C}$. FYI snow cover during SIMMS '93 was shallower than in previous years $(1990-92)-10 \mathrm{~cm}$ maximum in the crystal-pit area (Fig. 3c) and was predominantly composed of small, rounded grains (radius $0.3-0.5 \mu \mathrm{m}$ ) (Fig. 3b). Compared to FYI, the MYI surface is considerably more spatially heterogeneous. The floe's annual melt cycle encourages the development of hummocky surface features separated by depressed interstitial areas referred to here as melt-pond areas. In SIMMS '93, hummock tops consisted of a white frazil-like layer overlying darker blue ice, giving the hummocks a grey tone. Large melt-pond areas covered by a thick snow layer (Fig. 3c) were interspersed among these hummocks.

Figure $2 \mathrm{a}$ and $\mathrm{b}$ show albedo spectra collected during the early stage (triangle symbols) over FYI and MYI, respectively. Since both surfaces were covered by snow, the albedo at this stage was primarily controlled by the optical characteristics of the overlying snowpack. The albedo at both sites was high in the visible part of the spectrum (FYI $\alpha_{\text {vis }}=0.86$; MYI $\alpha_{\text {vis }}=0.89$ ) as most of the incident solar radiation is scattered out of the snowpack. In the near-infrared region, the albedo begins

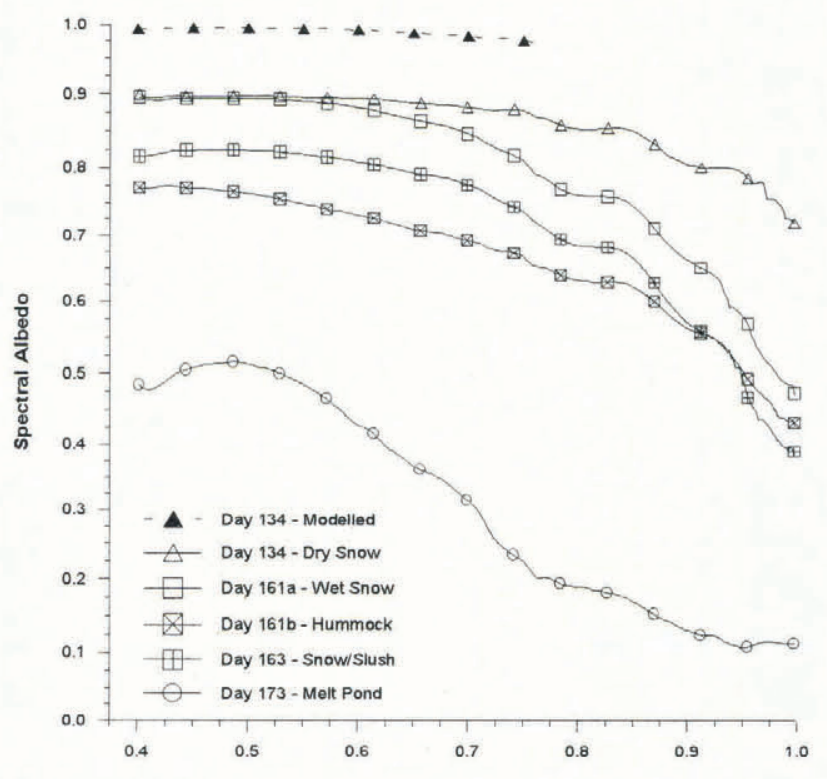

Fig. 2a. Spectral albedo measured over the first-year site in SIMMS'93. b. Spectral albedo measured over the multi-year site in SIMMS'93. ( $\Delta$, early stage, $\square$, transitional stage, $\bigcirc$, late stage) (symbols occur every 30 channels). 
Table 1. Average visible $(0.40 .77 \mu \mathrm{m})$ and near-infrared $(0.77-1.0 \mu \mathrm{m})$ albedo and coincidental geophysical data for albedo-sampling events. (Ilalics denote near-surface sample; brackets denole volume or daily average of variable; NA, not available

\begin{tabular}{|c|c|c|c|c|c|c|}
\hline \multirow[t]{2}{*}{ Spectrum } & \multirow[t]{2}{*}{ Visible albedo } & \multirow[t]{2}{*}{$\begin{array}{l}\text { Near-infrared } \\
\text { albedo }\end{array}$} & \multirow{2}{*}{$\begin{array}{l}\text { Snow depth } \\
\text { cm }\end{array}$} & \multirow{2}{*}{$\begin{array}{l}\text { Snow densily } \\
\qquad \mathrm{kg} \mathrm{m}^{-3}\end{array}$} & \multirow{2}{*}{$\begin{array}{l}\text { Snow wetness } \\
\% \text { by volume }\end{array}$} & \multirow{2}{*}{$\begin{array}{c}\text { Grain radius } \\
\text { } \mathrm{mm}\end{array}$} \\
\hline & & & & & & \\
\hline \multicolumn{7}{|l|}{ First-year ice } \\
\hline Day 135 snow & 0.86 & 0.77 & 10 & $349(307)$ & $3.1(4.0)$ & $0.48(0.96)$ \\
\hline Day 162 snow & 0.80 & 0.64 & 6 & $352(353)$ & $6.8(8.4)$ & $2.50(\mathrm{NA})$ \\
\hline Day 171 snow/ice & 0.71 & NA & 0 & & & $1.50(\mathrm{NA})$ \\
\hline Day 171 melt pond & 0.37 & 0.12 & & & & \\
\hline \multicolumn{7}{|l|}{ Multi-year ice } \\
\hline Day 134 snow & 0.89 & 0.82 & 48 & $243(335)$ & $1.7(0.5)$ & $0.25^{* * *}(\mathrm{NA})$ \\
\hline Day 161 snow & 0.87 & 0.67 & 62 & $503(401)$ & $3.0(1.2)$ & $1.5(\mathrm{NA})$ \\
\hline Day 161 hummock & 0.73 & 0.57 & & & & \\
\hline Day 163 snow/slush & 0.80 & 0.58 & $10^{+}$ & $384(452)^{*}$ & $6.3(6.0)^{*}$ & $4(\mathrm{NA})$ \\
\hline Day 163 slush/melt pond & 0.55 & 0.17 & & & & \\
\hline Day 173 melt pond & 0.41 & 0.15 & 0 & & & \\
\hline
\end{tabular}

* Data for day 164 used. "Average of day 13 and day $137 .{ }^{+}$Overlying $15 \mathrm{~cm}$ slush.

to decrease incrementally with wavelength. The visible and infrared characteristics of snow spectral albedo are controlled through the wavelength-dependent absorption characteristics of pure ice. Figure 4 shows the absorption coefficients for pure ice over the instrument's spectral sensitivity. It is evident that, over the spectral range

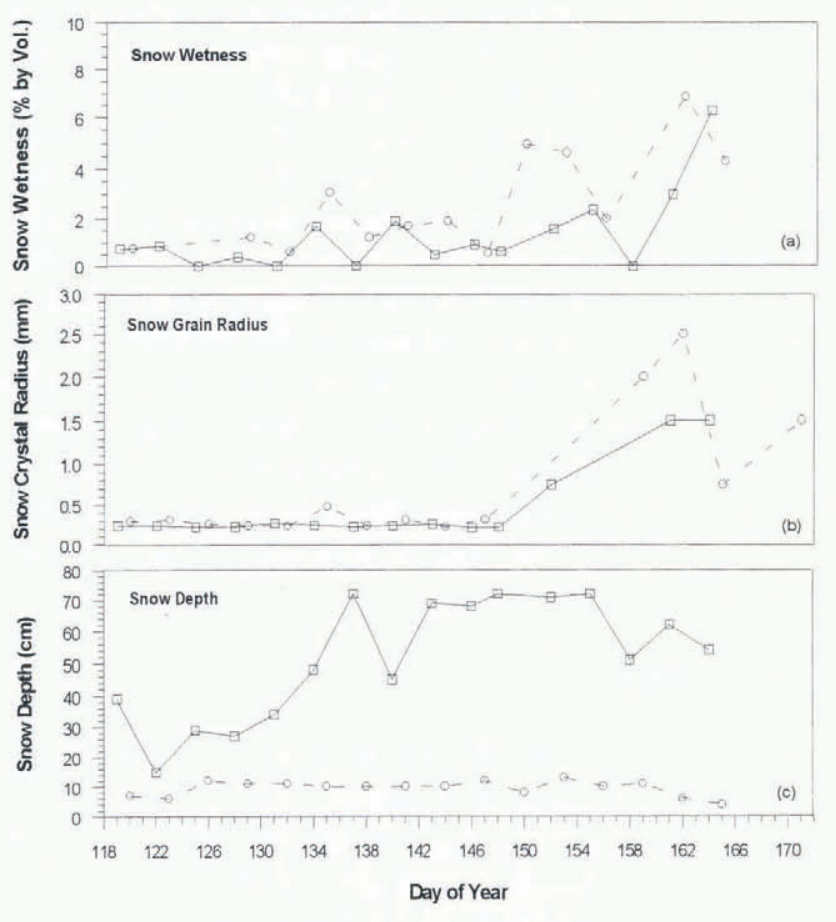

Fig. 3. Seasonal transition of snow properties at crystal pits: a. snow wetness (near-surface $3 \mathrm{~cm}$ laver); $b$. snowgrain radius (near-surface layer); (c) snow depth: $\bigcirc$, first-year-ice site; $\square$, multi-year-ice site. sampled, ice crystals are relatively transparent to incident radiation at visible wavelengths, but become moderately absorptive to infrared radiation (Wiscombe and Warren, 1980). In the early stage, visible light extinction in the overlying snow pack was dominated by multiple scattering by ice grains, resulting in a high surface albedo as the scattered light eventually left the volume. The incident near-infrared radiation was absorbed by ice crystals in the near-surface layers of the snowpack, thus reducing the albedo at these wavelengths. This absorption increased with wavelength following the absorption coefficient for pure ice.

Figure $2 \mathrm{a}$ and $\mathrm{b}$ also include modelled visible albedo for optically thick, pure snowpacks for days 135 (FYI) and 134 (MYI), respectively. Illumination and geophysical data of each sampling day were used as inputs to Wiscombe and Warren's (1980) snow-albedo model. The

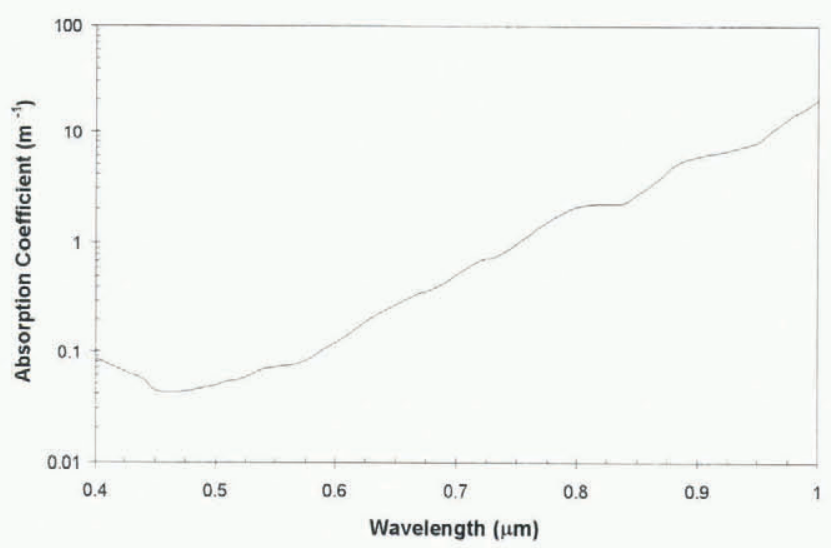

Fig. 4. Absorption coefficient of pure ice from 0.4 to $1.0 \mu \mathrm{m}$ (source: Grenfell and Perovich, 1981). 
modelled albedo averaged over the visible spectrum is 0.93 for the FYI site and 0.96 for the MYI site. It is evident that the magnitude of the measured visible albedo over both sites is lower than would be expected over an impurity-free, optically thick snow volume. One potential reason for the low visible albedo is the possibility that the snowpack was not optically thick, thus allowing the underlying, lower-albedo ice surface to reduce the visible albedo. Another possible reason would be the presence of impurities in the snow volume that were capable of absorbing visible radiation.

Dozier and others (1989) have shown that in order for the albedo of a snowpack composed of snow with radii of $1 \mathrm{~mm}$ to be independent of the albedo of the underlying surface (semi-infinite), a snow cover of at least $145 \mathrm{~mm}$ w.e. is required when incoming solar radiation at a wavelength of $0.45 \mu \mathrm{m}$ is incident at a solar zenith angle of $60^{\circ}$. Given the FYI snow volume's average grain-size of $0.96 \mathrm{~mm}$ and density of $307 \mathrm{~kg} \mathrm{~m}^{-3}$, a snow depth of $47 \mathrm{~cm}$ would be required before the effects of the underlying ice surface are negated and the volume could be considered optically thick for an incident wavelength at $0.45 \mu \mathrm{m}$. Since the snow cover on day 135 was far less $(10 \mathrm{~cm})$, we conclude that the snow cover was not optically thick and the underlying lower-albedo ice surface is the principal reason for the FYI surface's lower than expected visible albedo.

Since the snow cover on the MYI site was considerably deeper $(48 \mathrm{~cm})$ and composed of finer crystals, the underlying ice did not contribute to the visible albedo. The discrepancy between the modelled and sampled results for day 134 is probably due to the presence of absorbing particulates within the snowpack. Similarly, the lower albedo over the FYI site may also be partially due to impurities. Warren and Wiscombe (1980) have shown that grey absorbers within a snow volume, such as soot particles, can reduce the visible albedo of snow. Unfortunately, we are unable to verify this since snowimpurity measurements were not taken. If present, these particulates may have originated as wind-blown crustal material from nearby islands and/or soot from the nearby camp.

\subsection{Transitional stage}

The transitional stage was marked by the arrival of positive air temperatures which subsequently transformed FYI and MYI snow covers from a relatively low-water (funicular) state to a saturated, freely draining (pendular) volume. In this stage, the FYI site was covered by a thin, rapidly decomposing snow volume that allowed the underlying ice to appear as scattered grey patches. The MYI surface area was dominated by melt ponds filled with wet snow. In the transitional stage, snow covers over both ice types experienced significant increases in snow wetness and grain-size and decreases in snow depth (Fig. 3; Table 1). The dramatic increase in grain-size was due to the formation of large, polycrystalline aggregate grains by snow grains clustering to minimize surface free energy (Colbeck, 1979). Increases in liquid water can further increase the optically effective grain-size by filling pore spaces and coating grains (Dozier and others, 1981).

Spectra with square symbols in Figure $2 \mathrm{a}$ and $\mathrm{b}$ represent spectral albedo measured during the transitional stage. Compared to the early stage, the FYI visible albedo (day 162) decreased $6 \%$ as the snow depth decreased to $6 \mathrm{~cm}$ allowing the underlying ice surface to further reduce the surface albedo. By comparison, there was little change $(-2 \%)$ in the visible albedo of the MYI site (day 16la). It is evident that in terms of a deep, optically thick snow cover, changes in the snow's grain structure had little effect on the amount of visible radiation reflected out of the volume at this stage. The most dramatic changes in the spectral albedo of both ice types occurred at the longer, near-infrared wavelengths. The appearance of the large aggregate snow grains in the snow's surface layer increased the amount of absorbed infrared radiation, consequently lowering the nearinfrared albedo by $17-18 \%$ at both ice sites. In comparison to the MYI site, larger surface snow grains at the FYI site resulted in a lower near-infrared albedo (FYI $\alpha_{\text {nir }}=0.64$, MYI $\left.\alpha_{\text {nir }}=0.67\right)$. The inflection at $0.95 \mu \mathrm{m}$ in spectrum day 162 of Figure $2 \mathrm{a}$ is the result of instrument noise.

Warmer conditions led to increased exposure of ice hummocks on the floe. Spectrum day $16 \mathrm{lb}$ in Figure $2 \mathrm{~b}$ was collected over a hummock top adjacent to the crystalpit area. The hummock surface consisted of a thin, crusty, white ice layer covering milky-blue ice. The surface layer had apparently undergone preferential solar melting, making the darker-toned ice layer visible beneath it. The surface's spectral albedo appears to decrease linearly with wavelength from 0.5 to $0.8 \mu \mathrm{m}$. The upper ice layers of the hummock top scattered the incident light less efficiently than the thick melt-pond snow volumes, resulting in lower average visible and near-infrared albedos $\left(\alpha_{\text {vis }}=0.73 ; \alpha_{\text {nir }}=0.57\right)$ (Table 1$)$.

Two days later, melt-pond snow covers exhibited a dull colour as they approached saturation levels. Within the melt ponds, freely draining meltwater accumulated within lower snow layers, creating a darker sub-surface slush layer. Spectrum day 163 in Figure $2 \mathrm{~b}$ was collected in a melt-pond depression that consisted of a $15 \mathrm{~cm}$ blueslush layer covered by $10 \mathrm{~cm}$ of very wet snow. The thin snow cover allowed incident visible radiation to interact with the lower-albedo slush layer, decreasing visible albedo by $8 \%$ from day 161. Large polycrystalline aggregate grains at the surface (grain radius $=4 \mathrm{~mm}$ ) decreased the near-infrared albedo by $13 \%$ to 0.58 through increased absorption in near-surface zones. Overall, the appearance of a saturated snow surface in the transitional stage caused albedo to decrease across the instrument range, the largest decrease being at nearinfrared wavelengths.

\subsection{Late stage}

In the late stage, both FYI and MYI surfaces evolved into a heterogeneous mix of standing meltwater and bare snow/ice surfaces as air temperatures stayed consistently above $0^{\circ} \mathrm{C}$. The unique topography of MYI floes, having encouraged the accumulation of deep snow covers, led to the formation of water-filled melt ponds interspersed among the floe's hummocks. In comparison, increased meltwater drainage and flatter topography at the FYI site prevented the formation of deep water-filled melt ponds. 
In Figure 2a and b, spectra with circle symbols represent albedo measurements made during the late stage. Unlike the spectra from the previous stages, these data were collected on clear days. The melt-pond spectra appear to be correct, but the near-infrared part of the day 171a spectrum in Figure 2a is probably overestimated due to the response of the collector and thus truncated at $0.77 \mu \mathrm{m}$.

Spectrum day 17la in Figure 2a was taken over a white-ice area at the FYI site. The white patches were not drained ice areas, but rather thin, fragile remnants of the decomposed snow cover. This layer was very fragile and easily broke away to reveal a saturated blue-ice cover. The spectrum is slightly higher at the short, blue wavelengths indicating scattering by the dark, underlying ice layer. Spectra were collected over both FYI and MYI melt-pond areas. Spectrum day 171 b (Fig. 2a) was taken at the FYI site over a light-blue or aquamarine-coloured melt area $11 \mathrm{~cm}$ deep. A thin, frozen ice layer covered the surface. Most of the FYI surface was covered with meltwater. Spectrum day 173 (Fig. 2b) was measured at the MYI site over a milky-blue melt pond filled with $15 \mathrm{~cm}$ of meltwater. A thin $(<1 \mathrm{~cm})$, translucent, slush layer lay on the pond surface. At both ponds, solar energy incident at shorter wavelengths $(<0.5 \mu \mathrm{m})$ penetrated deeply into the underlying ice, while visible light at wavelengths $>0.5 \mu \mathrm{m}$ interacted more with the submerged surface ice layer (Perovich and Grenfell, 1981). This layer appears to scatter less efficiently, resulting in a decrease in albedo. At near-infrared wavelengths, absorption by meltwater clearly dominates as the albedo levels at an average value of 0.12 . The small amount of reflected radiation at these wavelengths is due to volume scattering in the pondsurface layers that were present at both sites.

\section{SUMMARY}

In SIMMS 93, the FYI site transformed from a highalbedo snow-covered surface to a low-albedo watercovered surface. The most dramatic changes occurred at near-infrared wavelengths. The high albedo of snowcovered sea ice was reduced when reduction in the snow volume's depth and enlargement of snow grains allowed incident radiation to interact with the darker, underlying ice surface. This decrease in surface albedo over the FYI site probably contributed to the early arrival of surface meltwater in 1993. The time of season when this critical depth is reached will vary depending on the ambient temperature and most importantly snow depth. The spring snow depth is dependent on the frequency of snowfall, which can serve to increase snow depth and reduce the volume's snow grain-size, and the opportunity for catchment to facilitate significant snow depths. The infrared sea-ice albedo responded to seasonal changes in the surface layers of the volume. When a snow cover was present, the seasonal growth of snow grains into polycrystalline units in the near-surface layer of the pack decreased infrared albedo. When surface water was present, the sea-ice surface was a radiation sink at infrared wavelengths. It should be noted that the SIMMS '93 experiment did not encompass the full melt season. With the appearance of the cracks in the ice, this FYI surface drained, probably revealing a higher-albedo ice surface (Grenfell and Perovich, 1984).

Like FYI, the MYI floe in SIMMS'93 transformed from a high- to low-albedo surface with the progression of the spring melt. Unlike the FYI site, at full melt conditions the MYI site was less homogenous due to the presence of the white hummocks interspersed among the melt ponds. The floe's overall albedo is thus dependent on its hummock/melt-pond ratio. It was evident that this ratio decreased as melt conditions evolved over the experiment period. Early in the melt season, the floe's melt-pond areas were filled with a thick snow cover which produced a higher albedo than the snow-covered FYI site. The infrared albedo was more sensitive to microstructural changes occurring in the snowpack's upper layers. The visible albedo stayed constant until increased water volumes in the pack resulted in the saturation of the cover's lower layers. As this slush layer grew and approached the snow/air interface, incident visible radiation scattering through the remaining snow layer is absorbed, consequently lowering the surface visible albedo. With the appearance of surface meltwater, both the visible and infrared albedos are reduced considerably. The shorter-wavelength visible radiation interacts more with the pond's bottom and underlying ice microstructure. Nearly all of the incident infrared radiation is absorbed within the meltwater, probably leading to the ablation of the pond's ice bottom and sides.

\section{CONGLUSION}

This investigation has examined the transformation of the spectral albedo of snow-covered first-year and multi-year ice surfaces with the onset of melt conditions. As expected, the albedo of sea ice during this period is intimately related to the geophysical structure of both the snow and ice volumes. The springtime metamorphism of snowpacks on both first-year and multi-year ice reduces surface albedo and increases the contrast between visible and near-infrared spectral albedo. Future field campaigns will provide an opportunity to extend this data set to encompass the full melt cycle (i.e. drainage and breakup). Of specific interest are improving the parameterization of sea-ice albedo in Earth system models and developing methodologies whereby remote-sensing data collected at solar and microwave wavelengths may be used to provide sea-ice albedo information useful for the development, initialization and validation of these models.

\section{ACKNOWLEDGEMENTS}

The authors would like to acknowledge the following agencies for their assistance with this work: the National Science and Engineering Research Council of Canada, the Institute of Space and Terrestrial Sciences, Northern Studies Scientific Training Grant and the Polar Continental Shelf Project. We thank the reviewers for their many constructive comments. A special thank you to all members of the SIMMS experiment team. 


\section{REFERENCES}

Allison, I., R.E. Brandt and S. G. Warren. 1993. East Antarctic sea ice; albedo, thickness distribution, and snow cover. 7. Geophys. Res., 98 C7), 12,417-12,429.

Colbeck, S. C. 1979. Grain clusters in wet snow. 7. Colloid Interface Sci., 72 (3), 371-384.

Dozier, J., S. R. Schneider and D. F. McGinnis, Jr. 1981. Effects of grain size and snowpack water equivalence on visible and near-infrared satellite observations of snow. Water Resour. Res., 17 4), 1213-1221.

Dozier, J., R. E. Davis and A. Nolin. 1989. Reflectance and transmittance of snow at high spectral resolution. IGARSS' 89.12 th Canadian Symposium on Remote Sensing. Quantitative remote sensing, an economic tool for the nineties, Vancouver, Canada, July 10-14, 1989. Volume 3, 662-664.

Grenfell, T.C. and D.K. Perovich. 1981. Radiation absorption coeflicients of polycrystalline ice from $400-1400 \mathrm{~nm}$. 7. Geophys. Res., 86 C8), 7447-7450.

Grenfell, T. C. and D. K. Perovich. 1984. Spectral albedos of sea ice and incident solar irradiance in the southern Beaufort Sea. J. Geophys. Res., 89 (C3), 3573-3580.

LeDrew, E. F. and D. G. Barber. 1994. The SIMMS program: a study of change and variability within the marine cryosphere. Arctic, 47 (3), 256-264.

Perovich, D. K. and T. C. Grenfell. 1981. Laboratory studies of the optical properties of young sea ice. f. Glaciol., 27 (96), 331-346.

Warren, S.G. and W.J. Wiscombe. 1980. A model for the spectral albedo of snow. II. Snow containing atmospheric aerosols. F. Atmos. Sci., $37(12), 27342745$.

Wiscombe, W.J. and S. G. Warren. 1980. A model for the spectral albedo of snow. 1. Pure snow. J. Almos. Sci., 37(12), 27122733. 